\title{
The relationship between body mass index, binge eating disorder and suicidality
}

Kristal Lyn Brown', Jessica Gokee LaRose ${ }^{1}$ and Briana Mezuk ${ }^{2,3^{*}}$ (D)

\begin{abstract}
Background: While restrictive and compensatory eating disorders (e.g. anorexia and bulimia) are associated with elevated risk of suicide, less is known about binge eating disorder (BED). There is suggestive evidence of a U-shaped relationship between body mass index (BMI) and completed suicide, but fewer studies on suicidal ideation or attempts. This study examined the association between BED, BMI, and suicidality, and assessed whether these relationships varied by gender.

Methods: Data come from the Collaborative Psychiatric Epidemiologic Surveys ( $N=14,497)$. Binge episodes and BED were assessed using the Composite International Diagnostic Inventory (CIDI). BMI was calculated from self-reported height and weight. Suicidal ideation/attempts were assessed using the CIDI. Weighted logistic regression was used to assess the association between binging/BED, BMI and suicidality. Interaction terms were used to assess whether the relationship between BMI and suicidality was moderated by binging/BED, and whether the relationships between binging/BED and BMI differed by gender.

Results: One-third of adults with BED had a history of suicidality, compared to $19 \%$ of those without. Both binging (OR: 1.95, 95\% Cl: 1.50-2.53) and BED (OR: 2.01, 95\% Cl: 1.41-2.86) were associated with suicidality in fully-adjusted models. BMI was associated with suicidality in a curvilinear manner, and this relationship was exacerbated by binging/BED (OR Binge eating x BMI: 1.04, 95\% Cl: 1.01-1.09, $p<0.05)$. The relationship between BMI and suicidality did not differ by gender $\left(\mathrm{OR}_{\text {gender }} \times \mathrm{BM}: 1.00, p<0.770\right)$. However, the relationship between binge eating and suicidality was stronger for women relative to men ( $\mathrm{OR}_{\text {gender }} \mathrm{x}$ binge: $\left.1.87, p<0.012\right)$.

Conclusions: Binge eating, even below the threshold for BED, is associated with suicidality. BMI is associated with suicidality in a curvilinear manner, and the BMl-suicidality relationship is potentiated by binge eating/BED. Findings support the thoughtful integration of psychiatric care into weight loss programs for adults with a history of binging behavior.
\end{abstract}

Keywords: Suicide, Binge eating disorder, Population-based, Gender, Obesity

\section{Background}

Binge Eating Disorder (BED) is characterized by consuming large amounts of food in a short period of time with a marked loss of control [1]. BED is the most common eating disorder in the United States (lifetime prevalence: $3.5 \%$ for women and $2 \%$ for men, although some estimates range as high as $8 \%)[1,2]$. Relatively little is

\footnotetext{
* Correspondence: bmezuk@umich.edu

${ }^{2}$ Department of Family Medicine and Population Health, Division of Epidemiology, Virginia Commonwealth University School of Medicine, Richmond, VA, USA

${ }^{3}$ Department of Epidemiology, University of Michigan School of Public Health, Ann Arbor, MI, USA

Full list of author information is available at the end of the article
}

known about the course and correlates of this condition as compared to other eating disorders (i.e., anorexia nervosa, bulimia nervosa) as BED was only included as a distinct diagnostic category in the 2013 edition of the Diagnostic and Statistical Manual of Mental Disorders (DSM) [3].

Eating disorders, including BED, are often co-morbid with other forms of psychopathology. For example, adults with BED report higher levels of anxious and depressive symptomology compared to adults without BED [4]. As with psychopathology in general, eating disorders are associated with elevated risk of suicidal behavior [4-7]. For example, numerous epidemiologic studies have shown

(C) The Author(s). 2018 Open Access This article is distributed under the terms of the Creative Commons Attribution 4.0 International License (http://creativecommons.org/licenses/by/4.0/), which permits unrestricted use, distribution, and 
that anorexia and bulimia nervosa are associated with risk of both attempted and completed suicide; [4, 6] however, only a handful of studies have examined the relationship between BED and suicidal behaviors $[4,8]$. In a study of women drawn from the Swedish registries, Pisetsky and colleagues (2013) reported that the risk of attempted suicide associated with BED was elevated similar to other eating disorders, although this estimate was based on only 64 cases of BED [5]. In their meta-analysis, Preti et al. (2010) reported that BED was not associated with completed suicide, although this was also based on a relatively small number of cases [6]. Finally, a more recent study by Suokas et al. (2013) using Finnish registry data reported that suicide mortality was not elevated among persons treated for BED [7]. To our knowledge, the relationship between BED and suicidality has not been examined in a population-based sample of US adults.

The relationship between obesity and psychopathology is complex and remains poorly understood [9]. Unlike other eating disorders (i.e. bulimia, anorexia), individuals with BED do not engage in restrictive or compensatory behaviors (e.g., excessive exercise, laxatives, vomiting). As a result, individuals with BED are at a higher risk for gaining weight and developing obesity. While most studies indicate that extreme obesity (i.e., BMI $\geq 35 \mathrm{~kg} / \mathrm{m}^{2}$ ) is positively associated with depression and other forms of psychopathology, [10-13] several reports suggest that the relationship between BMI and psychopathology is non-linear. For example, most studies report little or no difference in the prevalence of depression for BMI in the overweight and class 1 obesity range (i.e., BMI between $25 \mathrm{~kg} / \mathrm{m}^{2}$ and $35 \mathrm{~kg} / \mathrm{m}^{2}$ ) relative to normal weight, [11, $12,14]$ and several reports indicate that overweight is associated with lower likelihood of depression relative to normal or underweight $[11,13,15,16]$ particularly for non-Hispanic white populations [17]. The relationship between depression and obesity also appears to be more pronounced for women relative to men [18].

Consistent with this non-linear relationship between BMI and psychopathology, epidemiologic studies using mortality registries consistently report an inverse or inverted J-shaped relationship between BMI and completed suicide, such that suicide risk is highest among individuals with $\mathrm{BMI}<20 \mathrm{~kg} / \mathrm{m}^{2}$ (and, $\geq 35 \mathrm{~kg} / \mathrm{m}^{2}$, in those that report a J-shaped relationship), with lowest risk in the overweight and moderate obesity range [19-24]. A recent meta-analysis of 38 population-based studies reported that underweight was associated with elevated risk of suicide, and that overweight and obesity were associated with significantly lower risk of suicide, relative to normal weight [25]. While a handful of smaller studies indicate that extreme obesity $\left(\mathrm{BMI} \geq 40 \mathrm{~kg} / \mathrm{m}^{2}\right)$ is positively associated with suicidal behavior, $[25,26]$ most studies report an inverse linear relationship with BMI and suicidal ideation and attempts [26, 27]. Similar to the relationship between depression and obesity, there is suggestive evidence that this relationship between BMI and suicide may vary by gender [28]. However, few, if any, of these studies of BMI and completed suicide have accounted for history of eating disorders.

Suicide prevention requires the identification of novel risk factors for suicidal behaviors. Few large, population-based studies have examined whether binge eating behavior contributes to the relationship between BMI and suicidality. To this end, and building on prior research, the aim of this study was to determine the association between binge eating/BED, BMI and suicidality (i.e., ideation and attempts). We evaluated three hypotheses: (1) BED is associated with elevated likelihood of suicidality, (2) BMI is associated with likelihood of suicidality in a non-linear manner, and (3) The relationship between BED and suicidality is exacerbated by BMI. We also explored whether these relationships differed by gender.

\section{Methods \\ Participants and procedures}

Data are from the 2001-2003 Collaborative Psychiatric Epidemiologic Surveys (CPES). The CPES is a set of three nationally-representative cross-sectional householdsurveys (The National Comorbidity Survey Replication (NCS-R), The National Survey of American Life (NSAL), and the National Latino and Asian American Study (NLAAS)) conducted to estimate the prevalence of psychopathology in the adult (age $\geq 18)$ population and to assess treatment patterns, with specific attention to racial/ethnic minorities [29-31]. Additional details about the CPES study design and sampling approach are described elsewhere [29-31]. The CPES data used for this analysis are available through the Inter-University Consortium for Political and Social Research: https:// www.icpsr.umich.edu/icpsrweb/ICPSR/studies/20240.

This analysis was limited to individuals with complete data on BMI, BED, and suicidality $(N=14,497)$, which represents $72 \%$ of the total CPES sample. Those excluded from the analytic sample $(N=5516)$ were older, more likely to be male, more likely to be white, and had more education than those included; poverty-to-income ratio and BMI were similar (Additional file 1: Table S1). Most of those excluded were from the NCS-R, which by design only asked the complete set of BED items on a random subset of 2980 participants [32].

\section{Measures}

\section{Exposure ascertainment}

Lifetime history of BED (with hierarchy) was assessed using the World Health Organization's (WHO) expanded version of the Composite International Diagnostic Interview (CIDI) for DSM-IV [2]. BED case status 
was indicated if respondents endorsed binge eating, defined as (a) recurrent episodes of eating, in a discrete (2-h) period, an amount of food that is definitely larger than most people would eat during a similar period of time accompanied by (b) a sense of lack of control over eating, and (c) three or more cognitive or affective feelings during the binge (i.e., eating rapidly, eating until uncomfortably full, eating when not feeling hungry, eating alone due to feeling embarrassed by the amount of food consumed, feeling disgusted with oneself, depressed, or very guilty after overeating, or marked distress). These binge episodes had to occur at least 2 days a week for 6 months, and the binging could not be associated with use of compensatory behaviors (i.e. purging, fasting, excessive exercise), consistent with DSM-IV criteria. Individuals with bulimia or anorexia nervosa were excluded from the BED hierarchy diagnosis. Lifetime history of any binge episode was defined as criteria a and b only, and with duration of two days/week for at least three months. BMI $\left(\mathrm{kg} / \mathrm{m}^{2}\right)$ was calculated from self-reported weight and height. It was treated as a continuous variable (centered on the sample mean: $27 \mathrm{~kg} / \mathrm{m} 2$ ). As a sensitivity analysis we also evaluated BMI as a categorical variable using WHO categories $(<18.5,18.5$ to $<25$ (reference group), 25.0 to $<30$ and $\geq 30$ ).

\section{Outcome ascertainment}

Lifetime suicidality was indexed by a CIDI module that assessed suicidal ideation / intent (i.e., "seriously thought about committing suicide" or "made a plan for committing suicide") and suicide attempt, including the age of onset and recency of suicidality. For this analysis two dichotomous variables were created: for the main analysis we examined lifetime (ever/never) suicidality (ideation and/or intent), and for the sensitivity analyses we examined past-year suicidality; for the sensitivity analysis individuals who endorsed suicidality only prior to the past year were excluded $(n=2030)$.

We also conducted a post-hoc analysis examining lifetime history of attempting suicide as an outcome. Because of the skip-pattern of the CIDI, history of suicide attempt was only asked of those who endorsed suicidality; however, for this analysis we created a new variable indexing lifetime history of suicide attempt by recoding respondents who had not seriously considered suicide as a "no" for history of attempting suicide, as prior studies of this outcome have done. Due to some missing data on the attempt question, this analysis was limited to 13,079 respondents.

\section{Covariates}

All covariates were assessed by self-report and included age (in years, mean-centered at 43.4), race/ethnicity, gender, marital status, education and Income-to-needs ratio. Race/ethnicity was categorized as Asian, Hispanic,
Black, and Non-Latino White, with Black as the reference group. Education was categorized as high school education or less (reference group) vs. more than high school. Marital status was categorized as currently married (reference group), formerly married, and never married. Income-to-needs ratio is a measure of socioeconomic status calculated by dividing household income by the Census poverty threshold for that household size, [33] categorized into quintiles. We also considered smoking and medical comorbidities as confounders. Lifetime history of medical conditions (including arthritis, chronic pain, headaches, stroke, heart disease, hypertension, chronic lung disease, diabetes, and cancer) were summed and was categorized as zero (reference group), one, two, and three or more conditions for analysis. Smoking status was available on a subset of participants $(N=9648)$ and was categorized as current, former, and never smoker (reference group).

\section{Analytic approach}

Initial bivariate relationships between BED, suicidality and covariates were assessed using Scott-Rao chi-square tests. To address the first hypothesis, weighted logistic regression models were fit to test the association between binge eating behavior and lifetime history of suicidality as the dependent variable. Three nested models were fit for both BED and binge episodes: Model 1 was unadjusted, Model 2 was adjusted for BMI. Model 3 was adjusted for BMI and sociodemographic characteristics, and Model 4 was additionally adjusted for number of chronic health conditions; we also fit models additionally adjusted for smoking status as a sensitivity analysis. Weighted logistic regression models were fit to assess the relationship between BMI and suicidality using a similar nested model approach. To test the second hypothesis, we evaluated whether a quadratic term on BMI improved model fit, indicating a curvilinear relationship with suicidality. To test the third hypothesis, logistic regression models were fit that included interaction terms between BED (and binge eating) and BMI. To evaluate whether these relationships were similar for men and women these models were then fit within strata of sex. As a sensitivity analysis, all models were refit to examine the relationship between BED, binge eating, and BMI with past-year suicidality. Finally, we conducted two post-hoc sensitivity analyses: first, we refit all models examining binge eating as the exposure while excluding the 271 cases of BED from the analysis; and second, we refit all models to examine the outcome of lifetime history of suicide attempt rather than suicidality.

Goodness-of-fit was assessed using the Wald test. All analyses were conducted using STATA/IC 11.2 survey procedures to account for the complex sampling design and all $p$-values refer to two-tailed tests. 


\section{Results}

Approximately $4 \%$ of adults had a lifetime history of binge eating and $1.9 \%$ had a history of BED ( $48 \%$ of those who had history of bingeing) (Table 1). Respondents with
BED were younger, predominantly female and were more likely to have obesity relative to those without BED. Approximately $20 \%$ had a lifetime history of suicidality, with $4.0 \%$ in the past year, and $7.8 \%$ had attempted suicide at

Table 1 Sample Characteristics by lifetime history of binge episode and BED: Collaborative Psychiatric Epidemiologic Surveys

\begin{tabular}{|c|c|c|c|c|}
\hline & Lifetime binge episode & Never binge episode & Lifetime BED & Never BED \\
\hline $\bar{N}$ & 659 (3.9) & $13,838(96.1)$ & $271(1.9 \%)$ & $14,226(98.1 \%)$ \\
\hline Age (Mean, SE) & $38.6(1.0)$ & $43.0(0.3)$ & $40.4(1.4)$ & $42.9(0.3)$ \\
\hline Female gender & $424(62.6)$ & $8104(54.7)$ & $194(68.2)$ & $8334(54.8)$ \\
\hline \multicolumn{5}{|l|}{ Race } \\
\hline Asian & $82(6.9)$ & $2071(6.6)$ & $26(4.1)$ & $2127(6.6)$ \\
\hline Hispanic & $192(22.0)$ & $2936(15.9)$ & $79(19.3)$ & $3049(16.0)$ \\
\hline Black & $258(22.0)$ & $5243(17.3)$ & $94(16.7)$ & $5407(17.5)$ \\
\hline Non-Latino White & $127(49.1)$ & $3588(60.3)$ & $72(60.0)$ & $3643(60.0)$ \\
\hline \multicolumn{5}{|l|}{ Marital status } \\
\hline Currently married & $309(51.0)$ & $7396(57.2)$ & $133(53.1)$ & $7572(57.1)$ \\
\hline Divorced/widowed & $148(20.3)$ & 3040 (19.5) & $61(18.8)$ & 3127 (19.6) \\
\hline Never married & $202(28.7)$ & $3402(23.3)$ & $77(28.1)$ & $3527(23.4)$ \\
\hline \multicolumn{5}{|l|}{ Education } \\
\hline$\leq 12$ years & $380(53.6)$ & $7011(50.3)$ & $160(48.8)$ & 7231 (50.4) \\
\hline$>12$ years & $279(46.5)$ & $6827(49.7)$ & $111(51.2)$ & 6995 (49.6) \\
\hline \multicolumn{5}{|l|}{ Income-to-needs ratio } \\
\hline Quintile 1 & $248(29.8)$ & $3893(23.7)$ & $99(25.0)$ & $4042(24.0)$ \\
\hline Quintile 2 & $103(14.8)$ & $2419(16.3)$ & $43(14.5)$ & 2479 (16.2) \\
\hline Quintile 3 & $132(24.0)$ & $3339(25.3)$ & $53(26.2)$ & $3418(25.3)$ \\
\hline Quintile 4 & $75(12.7)$ & $1750(15.1)$ & $32(14.4)$ & $1793(15.0)$ \\
\hline Quintile 5 & $101(18.8)$ & 2437 (19.6) & $44(19.9)$ & 2494 (19.6) \\
\hline \multicolumn{5}{|l|}{ Smoking status } \\
\hline Never & $201(43.1)$ & $4814(46.6)$ & $94(42.6)$ & $4921(46.6)$ \\
\hline Former & $111(30.1)$ & $2293(27.2)$ & $51(38.3)$ & $2353(27.1)$ \\
\hline Current & $111(26.8)$ & $2118(26.2)$ & $41(19.2)$ & $2188(26.3)$ \\
\hline \multicolumn{5}{|l|}{ Number of chronic conditions } \\
\hline None & $371(43.3)$ & 8507 (46.2) & $138(37.7)$ & $8740(46.3)$ \\
\hline One & $130(21.0)$ & $2421(22.3)$ & $57(21.6)$ & $2494(22.3)$ \\
\hline Two & $63(12.1)$ & $1559(16.0)$ & $27(11.6)$ & $1595(15.9)$ \\
\hline Three or more & $95(23.7)$ & $1351(15.4)$ & $49(29.0)$ & $1397(15.5)$ \\
\hline BMI kg/m² (Mean, SE) & $29.8(0.4)$ & $27.1(0.1)$ & $31.0(0.6)$ & $27.2(0.1)$ \\
\hline \multicolumn{5}{|l|}{ BMI categories } \\
\hline$<25 \mathrm{~kg} / \mathrm{m}^{2}$ & $183(26.5)$ & $5606(40.7)$ & $58(17.0)$ & $5731(40.6)$ \\
\hline 25 to $<30 \mathrm{~kg} / \mathrm{m}^{2}$ & $195(33.1)$ & $4704(33.4)$ & $77(35.8)$ & $4822(33.3)$ \\
\hline 30 to $<35 \mathrm{~kg} / \mathrm{m}^{2}$ & $143(20.2)$ & $2214(16.2)$ & $71(26.2)$ & $2286(16.2)$ \\
\hline$\geq 35 \mathrm{~kg} / \mathrm{m}^{2}$ & $138(20.2)$ & $1314(9.6)$ & $65(20.9)$ & $1387(9.8)$ \\
\hline Lifetime history of suicidality & $198(34.2)$ & $2007(19.0)$ & $86(37.5)$ & 2119 (19.3) \\
\hline Lifetime history of suicide attempt & 89 (18.6) & $698(7.4)$ & $39(20.5)$ & $748(7.6)$ \\
\hline Past-year suicidality & $42(10.1)$ & $341(3.8)$ & $16(8.9)$ & $367(4.0)$ \\
\hline
\end{tabular}

Values are unweighted $\mathrm{N}$, weighted row percentages unless otherwise noted. $\mathrm{N}$ for smoking $=9648$ 
some point in their life. Among those with a history of binge eating, one-third (34.2\%) reported ever thinking about suicide, nearly one in five (18.6\%) had ever attempted suicide, and $10.1 \%$ experienced suicidality in the past year. These proportions were similar (37.5, 20.5 and $8.9 \%$, respectively) for BED. BMI was strongly right-skewed, and overall $26 \%$ of respondents had a BMI in the obesity range.

Concerning the first hypothesis, both binge eating (Crude Odds Ratio [OR]: 2.21, 95\% Confidence Interval [CI]: 1.67-2.92, $p<0.001$; Adjusted OR (AOR): 1.95, 95\% CI: $1.50-2.53, p<0.001$ ) and BED (Crude OR: 2.51 , 95\% CI: 1.79-3.50, $p<0.001$; AOR: 2.01 , 95\% CI: $1.41-2.86$, $p<0.001)$ were significantly associated with lifetime suicidality (Tables 2 and 3). Adding BMI to these models did not substantially attenuate the relationship between binge eating/BED and suicidality. Findings from the post-hoc sensitivity analysis of excluding cases of BED from the models examining binge eating were consistent with these findings (Additional file 1: Table S2). Results were also similar when examining the outcome of past-year suicidality.
The quadratic term on BMI was significant in the crude model $(p<0.004)$, and Fig. 1 illustrates the curvilinear relationship between BMI and lifetime suicidality by binge eating status. There was a modest but statistically significant relationship between BMI and suicidality (Additional file 2: Figure. S1), which was influenced by both number of chronic conditions and smoking status (Additional file 1: Table S3). Modeling BMI as a 4-level categorical variable illustrated a similar non-linear relationship with suicidality (Additional file 1: Table S4). These relationships were consistent when examining suicide attempts and past-year suicidality. Additional file 3: Figure S2 illustrates the curvilinear relationship between BMI and past year suicidality by lifetime binge eating status.

Turning to the third hypothesis, the interaction term between BMI and binge eating on likelihood of suicidality was statistically significant, even in fully-adjusted models $\left(\mathrm{OR}_{\text {Binge eating x BMI: }} 1.04,95 \% \mathrm{CI}: 1.01,1.09, p<0.021\right)$. The analysis of suicide attempt was similar $\left(\mathrm{OR}_{\text {Binge eating } x}\right.$ вмІ: $1.07,95 \%$ CI: $1.01,1.14, p<0.018)$. This interaction is illustrated by Fig. 1, which shows that the relationship between binge eating and suicidality was strongest for those

Table 2 Relationship between binge eating, BMI, and suicidal behavior

\begin{tabular}{|c|c|c|c|c|c|}
\hline & $\begin{array}{l}\text { Model } 1 \\
\text { OR (95\% Cl), p-value }\end{array}$ & $\begin{array}{l}\text { Model } 2 \\
\text { OR }(95 \% \text { Cl), p-value }\end{array}$ & $\begin{array}{l}\text { Model } 3 \\
\text { OR (95\% Cl), p-value }\end{array}$ & $\begin{array}{l}\text { Model } 4 \\
\text { OR }(95 \% \mathrm{Cl}) \text {, p-value }\end{array}$ & $\begin{array}{l}\text { Model } 5 \\
\text { OR }(95 \% \mathrm{Cl}), p \text {-value }\end{array}$ \\
\hline \multicolumn{6}{|l|}{ Outcome: Lifetime suicidality } \\
\hline Lifetime binge episode & $\begin{array}{l}2.21(1.67-2.92) \\
p<0.001\end{array}$ & $\begin{array}{l}2.11(1.62-2.74) \\
p<0.001\end{array}$ & $\begin{array}{l}2.09(1.61-2.73) \\
p<0.001\end{array}$ & $\begin{array}{l}1.95(1.50-2.53) \\
p<0.001\end{array}$ & $\begin{array}{l}1.80(1.34-2.42) \\
p<0.001\end{array}$ \\
\hline BMI (mean centered) & & $\begin{array}{l}1.00(0.99-1.02) \\
p<0.528\end{array}$ & $\begin{array}{l}1.00(1.00-1.03) \\
p<0.015\end{array}$ & $\begin{array}{l}1.02(0.99-1.02) \\
p<0.217\end{array}$ & $\begin{array}{l}1.01(1.00-1.03) \\
p<0.072\end{array}$ \\
\hline$B M I^{2}$ & & $\begin{array}{l}1.00(1.00-1.01) \\
p<0.003\end{array}$ & $\begin{array}{l}1.00(1.00-1.01) \\
p<0.219\end{array}$ & $\begin{array}{l}1.00(0.99-1.00) \\
p<0.218\end{array}$ & $\begin{array}{l}1.00(0.99-1.00) \\
p<0.239\end{array}$ \\
\hline $\mathrm{N}$ & 14,497 & 14,497 & 14,497 & 14,497 & 9648 \\
\hline \multicolumn{6}{|c|}{ Outcome: Lifetime suicide attempt } \\
\hline Lifetime binge episode & $\begin{array}{l}2.84(1.92-4.20) \\
p<0.001\end{array}$ & $\begin{array}{l}2.72(1.84-4.03) \\
p<0.001\end{array}$ & $\begin{array}{l}2.50(1.71-3.65) \\
p<0.001\end{array}$ & $\begin{array}{l}2.28(1.58-3.29) \\
p<0.001\end{array}$ & $\begin{array}{l}2.03(1.32-3.10) \\
p<0.001\end{array}$ \\
\hline BMI (mean centered) & & $\begin{array}{l}1.00(0.98-1.02) \\
p<0.744\end{array}$ & $\begin{array}{l}1.01(0.99-1.04) \\
p<0.211\end{array}$ & $\begin{array}{l}1.00(0.98-1.02) \\
p<0.848\end{array}$ & $\begin{array}{l}1.01(0.99-1.04) \\
p<0.318\end{array}$ \\
\hline$B M I^{2}$ & & $\begin{array}{l}1.00(1.00-1.01) \\
p<0.002\end{array}$ & $\begin{array}{l}1.00(1.00-1.01) \\
p<0.161\end{array}$ & $\begin{array}{l}1.00(1.00-1.01) \\
p<0.122\end{array}$ & $\begin{array}{l}1.00(1.00-1.01) \\
p<0.099\end{array}$ \\
\hline N & 13,079 & 13,079 & 13,079 & 13,079 & 8577 \\
\hline \multicolumn{6}{|c|}{ Outcome: Past-year suicidality } \\
\hline Lifetime binge eating & $2.80(1.72-4.56), p<0.001$ & $\begin{array}{l}2.79(1.76-4.42) \\
p<0.001\end{array}$ & $\begin{array}{l}2.51(1.68-3.76) \\
p<0.001\end{array}$ & $\begin{array}{l}2.33(1.53-3.55) \\
p<0.001\end{array}$ & $\begin{array}{l}2.18(1.36-3.51) \\
p<0.002\end{array}$ \\
\hline BMI (mean centered) & & $\begin{array}{l}0.99(0.96-1.02) \\
p<0.350\end{array}$ & $\begin{array}{l}1.01(0.98-1.05) \\
p<0.402\end{array}$ & $\begin{array}{l}1.01(0.97-1.04) \\
p<0.865\end{array}$ & $\begin{array}{l}1.01(0.97-1.05) \\
p<0.557\end{array}$ \\
\hline$B M I^{2}$ & & $\begin{array}{l}1.00(1.00-1.01) \\
p<0.001\end{array}$ & $\begin{array}{l}1.00(1.00-1.01) \\
p<0.166\end{array}$ & $\begin{array}{l}1.01(1.00-1.01) \\
p<0.155\end{array}$ & $\begin{array}{l}1.00(1.00-1.01) \\
p<0.153\end{array}$ \\
\hline $\mathrm{N}$ & 12,675 & 12,675 & 12,675 & 12,675 & 8267 \\
\hline
\end{tabular}




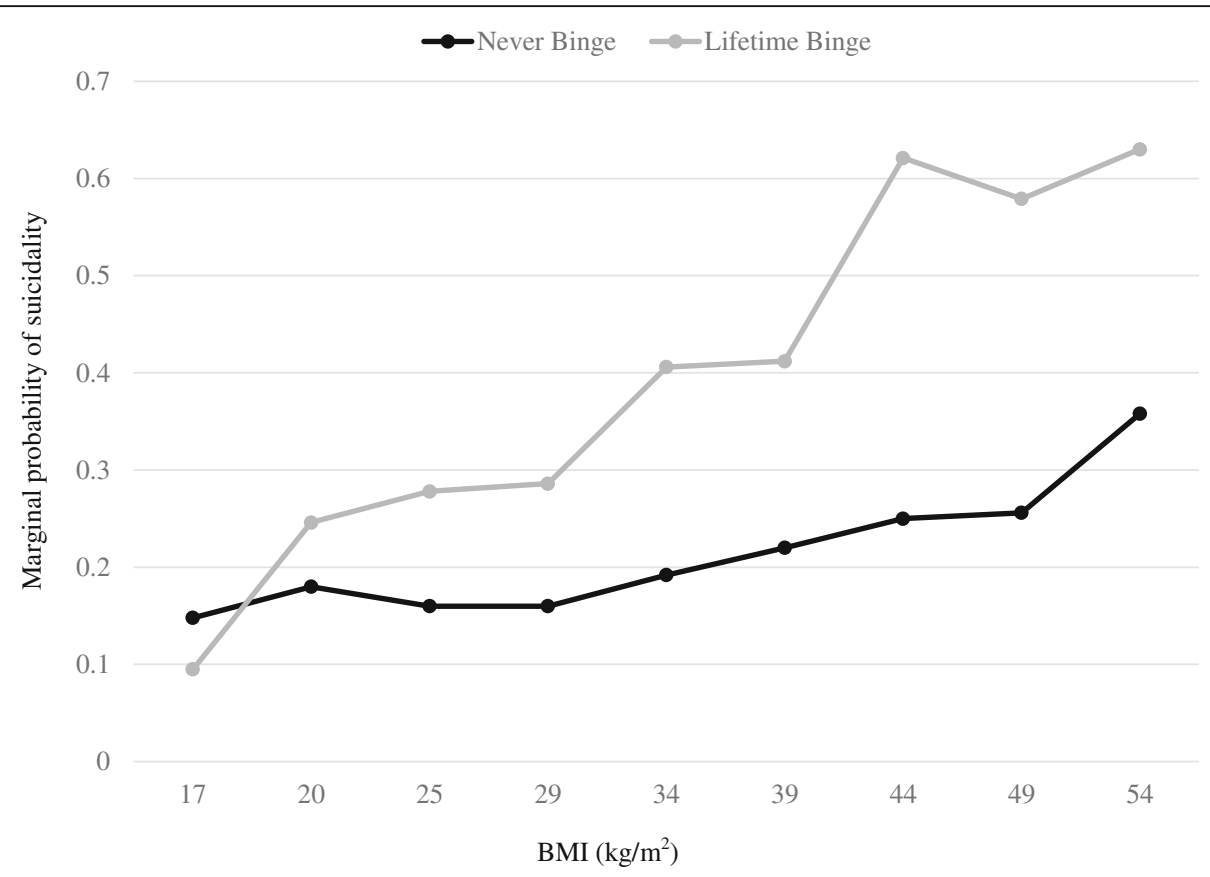

Fig. 1 Probability of lifetime suicidality by lifetime binge eating behavior at select BMI. Marginal predicted probability of lifetime suicidal ideation/ attempt by lifetime history of binge eating behavior by select BMI. Values are estimated at the sample mean for all model covariates (age, gender, race/ethnicity, marital status, income-to-needs ratio and chronic conditions). $N=14,497$

with higher BMI. For example, for adults with a BMI one standard deviation below the sample mean (approximately $20 \mathrm{~kg} / \mathrm{m}^{2}$ ) the relative odds of suicidality associated with binge eating was 1.38 ( $p=0.136)$; however, for those with a BMI 1.5 standard deviation above the sample mean (approximately $34 \mathrm{~kg} / \mathrm{m}^{2}$ ) the relative odds of suicidality associated with binge eating was $2.69(p<0.001)$.

Finally, we examined whether these relationships were consistent for men and women. There was no evidence that the relationship between BMI and suicidality differed by gender $\left(\mathrm{OR}_{\text {gender }}\right.$ x BMI: $\left.1.00, p<0.770\right)$. However, the relationship between binge eating and suicidality was stronger for women relative to men (OR gender $\mathrm{x}$ binge: $1.87, p<0.012)$. Figure 2 illustrates the relationship between binge eating and lifetime suicidality by gender at normal, overweight and obesity levels of BMI from fully-adjusted models. Results from the post-hoc analysis of lifetime suicide attempt were similar $\left(\mathrm{OR}_{\text {gender } \mathrm{X} \text { binge: }} 2.66, p<0.011\right)$.

\section{Discussion}

The primary finding from this study is that both binge eating behaviors and BMI are independently related to suicidal ideation and attempts among US adults. The relationship between BED and suicidality was not attenuated by BMI, indicating that BMI does not substantially explain the association between binge eating and suicidal behavior. However, there was evidence that the relationship between binge eating/BED and suicidality was exacerbated by high BMI. Consistent with prior work on BMI and completed suicide, the relationship between BMI and suicidality was non-linear, with highest risk associated with obesity relative to overweight, but with little difference in suicidality between underweight, normal, and overweight. These relationships were present for both genders, but the association between binge eating and suicidality was stronger for women relative to men. To our knowledge, this is the largest study to examine the relationship between BED, BMI, and suicidality in a diverse, nationally-representative sample of US adults.

The finding that binge eating/BED is associated with suicidality is consistent with the broader literature on eating disorders and associated psychiatric comorbidities [8]. Nearly one-third of women with BED report a lifetime history of suicidal Ideation and 15\% had attempted suicide [34]. Several reports have linked binge eating behaviors with mood disorders, [32] novelty-seeking, [35] and impulsiveness, [5, 36] which have in turn been linked to suicidal behaviors. To our knowledge, this study is the first to suggest that the relationship between binge eating and suicidality is moderated by BMI.

The linkages between BMI and suicidality are complex [24]. We found that the relationship between BMI and suicidality did not differ by gender, in contrast to several recent reports. Gao (2013) reported that the association between BMI and suicidality varied by gender and 
Table 3 Relationship between BED, BMI, and suicidal behavior

\begin{tabular}{|c|c|c|c|c|}
\hline & $\begin{array}{l}\text { Model } 1 \\
\text { OR (95\% Cl), p-value }\end{array}$ & $\begin{array}{l}\text { Model } 2 \\
\text { OR }(95 \% \mathrm{Cl}), p \text {-value }\end{array}$ & $\begin{array}{l}\text { Model } 3 \\
\text { OR }(95 \% \mathrm{Cl}), p \text {-value }\end{array}$ & $\begin{array}{l}\text { Model } 4 \\
\text { OR (95\% Cl) }\end{array}$ \\
\hline \multicolumn{5}{|c|}{ Outcome: Lifetime suicidality } \\
\hline Lifetime BED & $\begin{array}{l}2.51(1.79-3.50) \\
p<0.001\end{array}$ & $\begin{array}{l}2.35(1.72-3.23) \\
p<0.001\end{array}$ & $\begin{array}{l}2.10(1.52-2.90) \\
p<0.001\end{array}$ & $\begin{array}{l}2.01(1.41-2.86), \\
p<0.001\end{array}$ \\
\hline BMI (mean centered) & & $\begin{array}{l}1.00(0.99-1.02) \\
p<0.507\end{array}$ & $\begin{array}{l}1.01(0.99-1.02) \\
p<0.212\end{array}$ & $\begin{array}{l}1.01(1.00-1.03), \\
p<0.075\end{array}$ \\
\hline $\mathrm{BMI}^{2}$ & & $\begin{array}{l}1.01(1.00-1.01) \\
p<0.003\end{array}$ & $\begin{array}{l}1.00(1.00-1.00) \\
p<0.211\end{array}$ & $\begin{array}{l}1.00(1.00-1.01), \\
p<0.235\end{array}$ \\
\hline N & 14,497 & 14,497 & 14,497 & 9648 \\
\hline \multicolumn{5}{|c|}{ Outcome: Lifetime suicide attempt } \\
\hline Lifetime BED & $\begin{array}{l}3.11(2.11-4.59) \\
p<0.001\end{array}$ & $\begin{array}{l}2.96(2.02-4.34) \\
p<0.001\end{array}$ & $\begin{array}{l}2.40(1.73-3.32) \\
p<0.001\end{array}$ & $\begin{array}{l}2.31(1.60-3.32), \\
p<0.001\end{array}$ \\
\hline BMI (mean centered) & & $\begin{array}{l}1.00(0.98-1.02) \\
p<0.801\end{array}$ & $\begin{array}{l}1.00(0.98-1.02) \\
p<0.813\end{array}$ & $\begin{array}{l}1.01(0.99-1.04), \\
p<0.311\end{array}$ \\
\hline $\mathrm{BMI}^{2}$ & & $\begin{array}{l}1.00(1.00-1.01) \\
p<0.002\end{array}$ & $\begin{array}{l}1.00(1.00-1.00) \\
p<0.122\end{array}$ & $\begin{array}{l}1.00(1.00-1.01) \\
p<0.098\end{array}$ \\
\hline N & 13,079 & 13,079 & 13,079 & 8577 \\
\hline \multicolumn{5}{|c|}{ Outcome: Past-year suicidality } \\
\hline Lifetime BED & $\begin{array}{l}2.37(1.12-5.03) \\
p<0.025\end{array}$ & $\begin{array}{l}2.36(1.1304 .92) \\
p<0.022\end{array}$ & $\begin{array}{l}2.05(1.14-3.67) \\
p<0.017\end{array}$ & $\begin{array}{l}1.91(1.04-3.53), \\
p<0.039\end{array}$ \\
\hline BMI (mean centered) & & $\begin{array}{l}0.99(0.96-1.02) \\
p=0.430\end{array}$ & $\begin{array}{l}1.01(0.97-1.04) \\
p=0.822\end{array}$ & $\begin{array}{l}1.01(0.97-1.05), \\
p=0.537\end{array}$ \\
\hline $\mathrm{BMI}^{2}$ & & $\begin{array}{l}1.00(1.00-1.01) \\
p<0.001\end{array}$ & $\begin{array}{l}1.00(1.00-1.01) \\
p<0.173\end{array}$ & $\begin{array}{l}1.00(1.00-1.01), \\
p=0.168\end{array}$ \\
\hline N & 12,675 & 12,675 & 12,675 & 8267 \\
\hline
\end{tabular}

OR Odds ratio, $95 \%$ Cl $95 \%$ Confidence Interval

Model 1: Unadjusted. Model 2: Adjusted for BMI and BMI ${ }^{2}$. Model 3: Adjusted for BMI, race, gender, age, education, marital status, income to needs ratio, and number of chronic conditions. Model 4: Adjusted for BMl, race, gender, age, education, marital status, income to needs ratio, number of chronic conditions, and smoking status

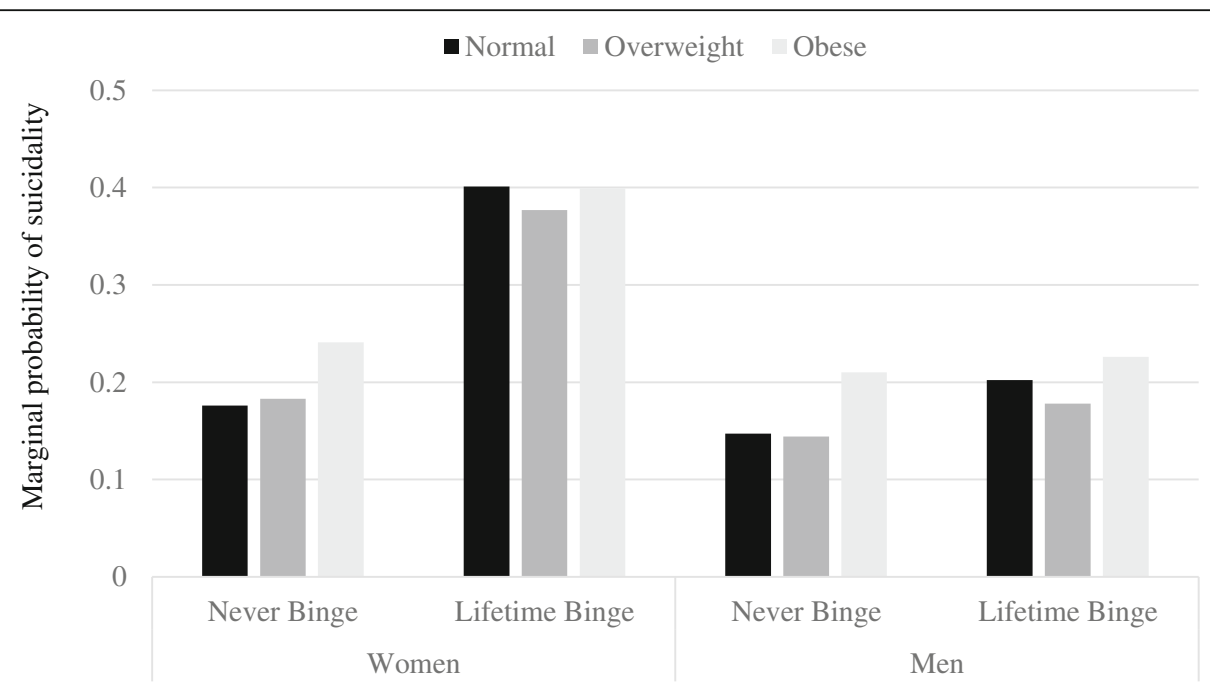

Fig. 2 Marginal probability of suicidality by gender and lifetime binge eating behavior. Marginal predicted probability of suicidal ideation/ attempts by lifetime history of binge eating behavior by gender and BMI category. Values are estimated at the sample mean for all model covariates (age, gender, race/ethnicity, marital status, income-to-needs ratio and chronic conditions). $N=14,497$ 
depression status, with an inverse relationship between BMI and suicide attempts among men regardless of depression history; and a curvilinear relationship among women, with higher incidence of attempts among low-BMI relative to normal weight women without history of depression, but a U-shared relationship among women with depression [19]. Kim et al. (2016) also reported that the relationship between BMI and suicidality was curvilinear and varied by gender in a large sample of Korean middle-aged adults [37]. Results from studies of BMI and suicidality among adolescent or young adult samples have generally been smaller and results are mixed $[25,38,39]$.

\section{Strengths and limitations}

The cross-sectional nature of our study precludes inferences regarding causality. However, our findings are consistent with prior literature on BED (and eating disorders more broadly) and suicidality, as well as BMI and completed suicide. Our analyses examining past-year suicidality and lifetime history of suicide attempt were consistent with our main results. BMI was calculated from self-reported weight and height, which tends underestimate BMI; [40] individuals with eating disorders tend give a more accurate account of their weight, likely because of greater weight-checking [40]. This analysis did not adjust for comorbid psychiatric conditions (i.e., major depression, general anxiety disorder) because these conditions are likely mediators of the BED (and potentially BMI) - suicidality relationship [32]. Finally, because of skip pattern in the CIDI the questions on suicide attempt were only asked of those who reported ideation; while it is logical to assume that persons who have not seriously considered suicide would not have attempted it, this may have missed attempts that were more impulsive in nature. This study also has a number of strengths. The large, diverse, representative sample reduces the risk of selection bias, BED was assessed using a reliable, structured diagnostic instrument, and the analysis accounted for medical comorbidities that likely confound the BMI-suicidality relationship.

\section{Conclusions}

Although more research is needed to decipher the complex relationships between BED, BMI, and suicidality, our findings can aid in understanding novel correlates of suicidality in the population. These findings complicate the ongoing debate about efforts to address eating disorders and the obesity endemic. With the adoption of BED in DSM-5, this will hopefully spur new conversations and debates about the relationships between weight, weight control messaging and interventions, and mental health.

\section{Additional files}

Additional file 1: Table S1. Comparison of respondents excluded from main analysis due to missing data. Table S2. Relationship between binge eating and $\mathrm{BMI}$ and with suicidal behavior, excluding respondent with a history of BED. Table S3. Relationship between BMI and lifetime suicidal behavior, not accounting for binge eating behavior. Table S4.

Relationship between BMI categories and lifetime suicidal behavior, not accounting for binge eating. (DOCX $30 \mathrm{~kb}$ )

Additional file 2: Figure S1. Probability of lifetime history of suicidality at select BMI. (DOCX $62 \mathrm{~kb}$ )

Additional file 3: Figure S2. Probability of past-year suicidality by lifetime binge eating behavior at select. (DOCX $24 \mathrm{~kb}$ )

\section{Abbreviations}

BED: Binge Eating Disorder; BMl: Body mass index; Cl: Confidence Interval; CIDI: Composite International Diagnostic Interview; CPES: Collaborative Psychiatric Epidemiologic Surveys; OR: Odds ratio

\section{Funding}

The CPES was supported by the National Institute of Mental Health (U01-MH57716, U01-MH60220, U01-MH62209 and U01-MH62207) with supplemental support from the Office of Behavioral and Social Sciences, the Substance Abuse and Mental Health Services Administration, the Robert Wood Johnson Foundation, and the University of Michigan. This analysis was supported in part by NIMH (K01-MH093642-A1) and the American Diabetes Association (1-16-ICTS-082).

\section{Availability of data and materials}

The CPES data used for this analysis are available through the Inter-University Consortium for Political and Social Research: https://www.icpsr.umich.edu/ icpsrweb/ICPSR/studies/20240. umich.edu/icpsrweb/CPES/.

\section{Authors' contributions}

KLB conceptualized the study, assisted with the analysis, and wrote the first draft of the manuscript. BM assisted with the study design, conducted the analysis, and provided substantial input to the writing of the manuscript. JGL provided critical review and editing of the manuscript. All authors read and approved the final version of the manuscript for publication.

Ethics approval and consent to participate

All participants in the CPES provided informed consent. This analysis used only publicly-available data and thus was exempt from human subjects regulations.

\section{Competing interests}

The authors declare that they have no competing interests

\section{Publisher's Note}

Springer Nature remains neutral with regard to jurisdictional claims in published maps and institutional affiliations.

\section{Author details}

${ }^{1}$ Department of Health Behavior and Policy, Virginia Commonwealth University School of Medicine, Richmond, VA, USA. ${ }^{2}$ Department of Family Medicine and Population Health, Division of Epidemiology, Virginia Commonwealth University School of Medicine, Richmond, VA, USA. ${ }^{3}$ Department of Epidemiology, University of Michigan School of Public Health, Ann Arbor, MI, USA.

Received: 14 March 2018 Accepted: 23 May 2018 Published online: 15 June 2018

\section{References}

1. Cossrow N, Pawaskar M, Witt EA, Ming EE, Victor TW, Herman BK, et al. Estimating the prevalence of binge eating disorder in a community sample from the United States: comparing DSM-IV-TR and DSM-5 criteria. J Clin Psychiatry. 2016;77(8):e968-74. 
2. Kessler RC, Berglund PA, Chiu WT, Deitz AC, Hudson Jl, Shahly V, et al. The prevalence and correlates of binge eating disorder in the World Health Organization world mental health surveys. Biol Psychiatry. 2013;73:904-14.

3. American Psychiatric Association. Diagnostic and statistical manual of mental disorders (DSM-5). Arlington: American Psychiatric Association; 2013.

4. Kostro K, Lerman JB, Attia E. The current status of suicide and self-injury in eating disorders: a narrative review. J Eat Disord. 2014;2:19.

5. Pisetsky E, Thornton L, Lichtenstein P, Pedersen N, Bulik C. Suicide attempts in women with eating disorders. J Abnorm Psychol. 2013;122:1042-56.

6. Preti A, Rocchi MBL, Sisti D, Camboni MV, Miotto P. A comprehensive metaanalysis of the risk of suicide in eating disorders. Acta Psychiatr Scand. 2011; 124:6-17.

7. Suokas JT, Suvisaari JM, Gissler M, Löfman R, Linna MS, Raevuori A, et al. Mortality in eating disorders: a follow-up study of adult eating disorder patients treated in tertiary care, 1995-2010. Psychiatry Res. 2013;210:1101-6.

8. Smith AR, Zuromski KL, Dodd DR. Eating disorders and suicidality: what we know, what we don't know, and suggestions for future research. Curr Opin Psychol. 2017;22:63-7.

9. Ball K, Brown W, Crawford D. Who does not gain weight? Prevalence and predictors of weight maintenance in young women. Int J Obes Relat Metab Disord. 2002;26:1570-8.

10. Luppino FS, de Wit LM, Bouvy PF, Stijnen T, Cuijpers P, Penninx BWJH, et al. Overweight, obesity, and depression: a systematic review and meta-analysis of longitudinal studies. Arch Gen Psychiatry. 2010;67:220-9.

11. Ma J, Xiao L. Obesity and depression in US women: results from the 20052006 National Health and nutritional examination survey. Obesity (Silver Spring). 2010;18:347-53.

12. Onyike CU, Crum RM, Lee HB, Lyketsos CG, Eaton WW. Is obesity associated with major depression? Results from the third National Health and nutrition examination survey. Am J Epidemiol. 2003;158:1139-47.

13. Zhao G, Ford ES, Dhingra S, Li C, Strine TW, Mokdad AH. Depression and anxiety among US adults: associations with body mass index. Int J Obes. 2009:33:257-66.

14. Simon GE, Ludman EJ, Linde JA, Operskalski BH, Ichikawa L, Rohde P, et al. Association between obesity and depression in middle-aged women. Gen Hosp Psychiatry. 2008;30:32-9.

15. Bjerkeset O, Romundstad P, Evans J, Gunnell D. Association of adult body mass index and height with anxiety, depression, and suicide in the general population: the HUNT study. Am J Epidemiol. 2008;167:193-202.

16. Goldney RD, Dunn KI, Air TM, Dal Grande E, Taylor AW. Relationships between body mass index, mental health, and suicidal ideation: population perspective using two methods. Aust N Z J Psychiatry. 2009:43:652-8.

17. Hicken MT, Lee H, Mezuk B, Kershaw KN, Rafferty J, Jackson JS. Racial and ethnic differences in the association between obesity and depression in women. J Women's Health (Larchmt). 2013:22:445-52.

18. de Wit L, Luppino F, van Straten A, Penninx B, Zitman F, Cuijpers P. Depression and obesity: a meta-analysis of community-based studies. Psychiatry Res. 2010;178:230-5.

19. Gao S, Juhaeri J, Reshef S, Dai WS. Association between body mass index and suicide, and suicide attempt among British adults: the health improvement network database. Obesity (Silver Spring). 2013;21:E334-42.

20. Kaplan MS, McFarland BH, Huguet N. The relationship of body weight to suicide risk among men and women: results from the US National Health Interview Survey Linked Mortality File. J Nerv Ment Dis. 2007;195:948-51.

21. Magnusson PKE, Rasmussen F, Lawlor DA, Tynelius P, Gunnell D. Association of body mass index with suicide mortality: a prospective cohort study of more than one million men. Am J Epidemiol. 2006;163:1-8.

22. McCarthy JF, Ilgen MA, Austin K, Blow FC, Katz IR. Associations between body mass index and suicide in the veterans affairs health system. Obesity (Silver Spring). 2014;22:269-76.

23. Mukamal K, Kawachi I, Miller M, Rimm EB. Body mass index and risk of suicide among men. Arch Intern Med. 2007;167:468-75.

24. Perera S, Eisen RB, Dennis BB, Bawor M, Bhatt M, Bhatnagar N, et al. Body mass index is an important predictor for suicide: results from a systematic review and meta-analysis. Suicide Life Threat Behav. 2016;46:697-736.

25. Dutton GR, Bodell LP, Smith AR, Joiner TE. Examination of the relationship between obesity and suicidal ideation. Int J Obes. 2013:37:1282-6.

26. Batty GD, Whitley E, Kivimäki M, Tynelius P, Rasmussen F. Body mass index and attempted suicide: cohort study of 1,133,019 Swedish men. Am J Epidemiol. 2010;172:890-9.
27. Sörberg A, Gunnell D, Falkstedt D, Allebeck P, Åberg M, Hemmingsson T. Body mass index in young adulthood and suicidal behavior up to age 59 in a cohort of Swedish men. PLoS One. 2014;9:e101213.

28. Zhang J, Yan F, Li Y, McKeown RE. Body mass index and suicidal behaviors: a critical review of epidemiological evidence. J Affect Disord. 2013;148:147-60.

29. Alegria M, Takeuchi D, Canino G, Duan N, Shrout P, Meng X-L, et al. Considering context, place and culture: the National Latino and Asian American study. Int J Methods Psychiatr Res. 2004;13:208-20.

30. Jackson JS, Torres M, Caldwell CH, Neighbors HW, Nesse RM, Taylor RJ, et al. The National Survey of American life: a study of racial, ethnic and cultural influences on mental disorders and mental health. Int J Methods Psychiatr Res. 2004;13:196-207.

31. Kessler RC, Berglund P, Chiu WT, Demler O, Heeringa S, Hiripi E, et al. The US National Comorbidity Survey Replication (NCS-R): design and field procedures. Int J Methods Psychiatr Res. 2004;13:69-92.

32. Forrest LN, Zuromski KL, Dodd DR, Smith AR. Suicidality in adolescents and adults with binge-eating disorder: results from the national comorbidity survey replication and adolescent supplement. Int J Eat Disord. 2017;50:40-9.

33. Proctor BD, Dalaker J. Poverty in the United States: 2001. Current Population Reports [Internet]. Superintendent of Documents, U; 2002 [cited 2017 Aug 30]. Available from: https://eric.ed.gov/?id=ED469530

34. Swanson SA, Crow SJ, Le Grange D, Swendsen J, Merikangas KR. Prevalence and correlates of eating disorders in adolescents. Results from the national comorbidity survey replication adolescent supplement. Arch Gen Psychiatry. 2011;68:714-23.

35. Grucza RA, Przybeck TR, Cloninger CR. Prevalence and correlates of binge eating disorder in a community sample. Compr Psychiatry. 2007;48:124-31.

36. Ural C, Belli H, Akbudak M, Solmaz A, Bektas ZD, Celebi F. Relation of binge eating disorder with impulsiveness in obese individuals. World J Psychiatry. 2017:7:114-20.

37. Kim D-K, Song HJ, Lee E-K, Kwon J-W. Effect of sex and age on the association between suicidal behaviour and obesity in Korean adults: a cross-sectional nationwide study. BMJ Open. 2016;6:e010183.

38. Crow S, Eisenberg ME, Story M, Neumark-Sztainer D. Suicidal behavior in adolescents: relationship to weight status, weight control behaviors, and body dissatisfaction. Int J Eat Disord. 2008;41:82-7.

39. Zuromski KL, Cero I, Witte TK, Zeng P. The quadratic relationship between body mass index and suicide ideation: a nonlinear analysis of indirect effects. Suicide Life Threat Behav. 2017;47:155-67.

40. Barnes RD, White MA, Masheb RM, Grilo CM. Accuracy of self-reported weight and height and resulting body mass index among obese binge eaters in primary care: relationship with eating disorder and associated psychopathology. Prim Care Companion J Clin Psychiatry. 2010;12

\section{Ready to submit your research? Choose BMC and benefit from:}

- fast, convenient online submission

- thorough peer review by experienced researchers in your field

- rapid publication on acceptance

- support for research data, including large and complex data types

- gold Open Access which fosters wider collaboration and increased citations

- maximum visibility for your research: over $100 \mathrm{M}$ website views per year

At BMC, research is always in progress.

Learn more biomedcentral.com/submissions 